\title{
Zur Ideologie der Arbeiterdichtung
}

Eine wissenssoziologische Untersuchung

\author{
INAUGURAL-DISSERTATION \\ zur \\ Erlangung der Doktorwürde \\ der \\ Philosophischen Fakultät \\ der Philipps-Universität Marburg/Lahn
}

\author{
Vorgelegt von \\ Christoph Rülcker \\ aus Dresden
}

Marburg/Lahn I969 
Die vorliegende Arbeit ist unter dem Titel „Ideologie der Arbeiterdichtung I9I4-I933“ im Buchhandel erschienen. J. B. Metzlersche Verlagsbuchhandlung Stuttgart

ISBN 978-3-476-99892-7 ISBN 978-3-476-99891-0 (eBook)

DOI 10.1007/978-3-476-99891-0

Von der Philosophischen Fakultät der Philipps-Universität Marburg/Lahn als Dissertation angenommen am Ir. II. 1969

Tag der mündlichen Prüfung: I4. 2. 1970

Berichterstatter: Prof. Dr. Heinz Maus

Mitberichterstatter: Prof. Dr. Wolfgang Abendroth

Mitberichterstatter: Prof. Dr. Gerhard Heilfurth 
INHALT

Einleitung . . . . . . . . . . . . . . . . . . . . I

Abgrenzung .. . . . . . . . . . . . . . . . . . I2

Identifikation der $>$ Arbeiterdichter mit dem Staat . . . . . . . . . . 39

Irrationalismus in der >Arbeiterdichtungs . . . . . . . . . . . . . 57

Die Behandlung der Realität . . . . . . . . . . . . . . . 80

Schluß . . . . . . . . . . . . . . . . . . I05

Anmerkungen ....................... . IIo

Anhang . . . . . . . . . . . . . . . . . . I47

Literaturverzeichnis . . . . . . . . . . . . . . . I I I 
IDEOLOGIE DER

ARbEITERDICHTUNG

I9I4-I933 